\title{
Class II Furcations Treated by Guided Tissue Regeneration in Humans: Case Reports
}

\author{
R.G. Caffesse, ${ }^{*}$ B.A. Smith, ${ }^{\dagger}$ B. Duff, ${ }^{\ddagger}$ E.C. Morrison, ${ }^{*}$ D. Merrill,${ }^{\S}$ and W. Becker
}

IN THE CASES REPORTED HERE, the response of Class II mandibular molar furcation defects to guided tissue regeneration (GTR) versus sham operation was evaluated. Baseline information, including probing pocket depth (PD) and clinical attachment level (CAL) measurements, was recorded after completion of the hygienic phase. Eleven experimental and six control furcations, randomly assigned, are included in this report. The furcations were surgically exposed, using a flap approach and the areas were debrided. On the experimental teeth, Gore-Tex periodontal material was adapted and sutured, using a suspensory suture. The flaps were then sutured tightly, assuring complete coverage to the material. For 1 month all patients were seen weekly and rinsed their mouths with an $0.12 \%$ chlorhexidine solution daily. After 4 to 6 weeks the Gore-Tex membranes were removed. Clinical measurements were repeated at 3 and 6 months following surgery. Changes from baseline in PD and CAL were calculated for each case. Results indicated that PD measurements were reduced by both procedures, but the reduction was better for GTR at 3 and 6 months. At six months the test sites showed $2.8 \pm 1.0 \mathrm{~mm}$ pocket reduction, while the control sites showed an average of $1.6 \pm 0.9$ $\mathrm{mm}$ reduction in pocket depth. CAL recordings were improved by both treatments, but were better for GTR at 6 months, with an average gain in CAL of $1.8 \mathrm{~mm}$ for the GTR and $0.6 \mathrm{~mm}$ for the controls. These cases in which GTR was compared to sham-operated controls indicate that GTR can improve the response to therapy of Class II furcation defects. J Periodontol 1990; 61:510-514.

Key Words: Periodontal pockets/surgery; furcation defects/therapy; guided tissue regeneration.

Although it has been shown that it is possible to achieve new attachment in areas previously exposed to the periodontal pocket, the predictability of such procedures is still very low. In recent years a more predictable way has been postulated to promote new attachment by allowing cells from the remaining periodontal membrane to proliferate, migrate, and repopulate the exposed root surface. This is called guided tissue regeneration (GTR). ${ }^{1-3}$

Animal studies have documented the benefits of guided tissue regeneration procedures in achieving different degrees of periodontal regeneration. ${ }^{1,4-7}$ Clinical reports have also corroborated such beneficial results in humans. ${ }^{2,8}$ Gottlow et al., ${ }^{9}$ Becker et al., ${ }^{10}$ and Becker et al. ${ }^{11}$ have pre-

\footnotetext{
*The University of Texas Health Science Center at Houston, Dental Branch, Houston, TX.

${ }^{\ddagger}$ The University of Michigan, Ann Arbor, MI.

*Private practice, Fairfield, $\mathrm{OH}$.

sPrivate practice, Grand Blanc, MI.

"Private practice, Tucson, AZ.
}

sented clinical cases evaluated biometrically and a few histologically, indicating that GTR can lead to periodontal regeneration. In two recent reports, Pontoriero et al. ${ }^{12,13}$ presented the results of the first clinical study evaluating the effects of GTR in furcation involvement.

Clinical experience has indicated that GTR has the best possibility of success in Class II furcation involvement and deep intrabony defects.

The purpose of this study was to evaluate in humans the clinical efficacy of guided tissue regeneration in the treatment of Class II furcation defects due to periodontitis.

\section{MATERIALS AND METHODS}

Nine patients diagnosed as having moderate to advanced chronic periodontitis participated in this study. They were undergoing periodontal therapy at the Graduate Periodontics Clinic, Department of Periodontics, The University of Michigan. They presented with Class II furcation defects in mandibular molars. These lesion sites exhibited adequate 
amounts of keratinized tissue, with gingiva covering the opening of the furcation. Patients gave informed consent prior to the experimental procedure.

After completion of the hygiene phase of therapy, the teeth were surgically treated, raising a mucoperiosteal flap with an intrasulcular incision or a reverse bevel incision. When an intrasulcular incision was used, the inner aspect of the flap was curetted after its elevation. Thorough root instrumentation and debridement of the area followed, which was accomplished by hand and rotary instrumentation.

Teeth were randomly assigned as experimental or control. If experimental, a piece of Gore-Tex" periodontal material was cut to fit the size and shape of the surgically exposed area, completely covering the opening of the furcation. It was closely adapted to the root and sutured with a suspensory suture around the tooth, using a Gore-Tex 40 suture with a FS2 needle. The flaps were repositioned and tightly sutured with interproximal figure-of-eight sutures, using the same material. It was assured that the flaps covered the periodontal material completely and gained close adaptation to the tooth.

The control teeth were treated similarly, with the exception that the periodontal material was not placed. No dressings were placed, and chlorhexidine digluconate $0.12 \%$ was prescribed for daily use for 4 weeks.

All patients were seen once a week for the first 4 postoperative weeks and received maintenance prophylaxes at 3 and 6 months. Four to 6 weeks after placement, the GoreTex periodontal material was removed. Under infiltrative anesthesia, the Gore-Tex sutures were cut, if still present, a split thickness flap was raised, the suture cut, the membrane retrieved, and the tissues sutured back covering the newly formed tissue in the furcation. These sutures were removed in 1 week.

\section{Clinical Evaluation}

Prior to surgery (post-hygiene phase) and at 3 and 6 months post-surgery, the following parameters were evaluated: Plaque Index,${ }^{14}$ Gingival Index,${ }^{15}$ probing pocket depth, and clinical attachment levels. ${ }^{16}$

Probing measurements were recorded on six points around each tooth; the furcation area was also probed on the mesial of the distal root and on the distal of the mesial root. Additionally, a horizontal measurement was taken from the convexities of the roots to the depth of penetration at the fornix of the furcation.

\section{RESULTS}

This report includes the results of 13 teeth treated, 9 experimental and 4 control. The sample included 7 males and 2 females with ages ranging from 32 to 76 years.

All sites treated healed uneventfully. Clinically, the ex-

W.L. Gore and Associates, Flagstaff, AZ. perimental sites tolerated the implantation of the Gore-Tex periodontal material without complications (Fig. 1).

Experimental and control sites showed similar trends, regarding plaque and gingivitis for all experimental periods (Table 1).

The values for probing pocket depth and clinical attachment levels reported here have been calculated, using only the measurements recorded in the furcations. Table 2 shows the values of probing pocket depth for experimental and control sites at different time points. Baseline values were recorded before surgery (after hygienic phase). Mean pocket depths at baseline were deeper in the test group than in the control. Similar values were recorded at 3 and 6 months. Table 3 shows mean changes from baseline probing pocket depth. Both at 3 and 6 months these changes were better for the test than the control sites.

Results for clinical attachment levels are presented in Tables 4 and 5. Mean values were similar at all time points. When differences from baseline were compared, the results were better for the test sites. No changes in horizontal attachment values were found (Table 6).

\section{DISCUSSION}

The present results demonstrate the beneficial effects of GTR when treating Class II furcation defects, as evaluated clinically. Since Nyman et al. ${ }^{2}$ showed in 1982 the possibilities for regeneration of the periodontal support when treating a lower incisor tooth in one patient, other reports have corroborated this possibility in both humans and animals. Gottlow et al. ${ }^{9}$ reported clinical cases, including the treatment of different types of defects with positive results. Becker et al. reported similar results in two publications. ${ }^{10,11}$ In 1988, Becker et al. ${ }^{11}$ evaluated results of a treated population according to the topography of the defect. They reported a mean probing depth reduction of 3.13 $\mathrm{mm}$ and a mean gain of clinical attachment of $2.3 \mathrm{~mm}$ after 6 months for 6 Class II furcations treated. Our corresponding values for the test teeth were $2.8 \mathrm{~mm}$ and $1.8 \mathrm{~mm}$, respectively. The reason for these differences could be explained by the methodology of probing. While we recorded probing depth and clinical attachment in the furcation, using 2 locations on the furcation aspects of mesial and distal roots; Becker et al. used only one measurement in the middle of the furcation, away from the root surfaces. Consequently, our present recordings may better reflect what actually happens with these clinical parameters.

The only studies available reporting test and control groups are those of Pontoriero et al. ${ }^{12,13}$ In a short communication in $1987,,^{12}$ they reported the treatment of 21 test Class II furcations and 21 controls. At 6 months, 14 test sites were completely closed, and 5 showed defect depths of less than $1 \mathrm{~mm}$. The controls showed 2 furcations closed and 5 with depths of $2 \mathrm{~mm}$ or less. The results of the same study reported ${ }^{13}$ by the authors in 1988 indicated mean probing depth reductions in the furcation of $4.0 \mathrm{~mm}$ for the test, 

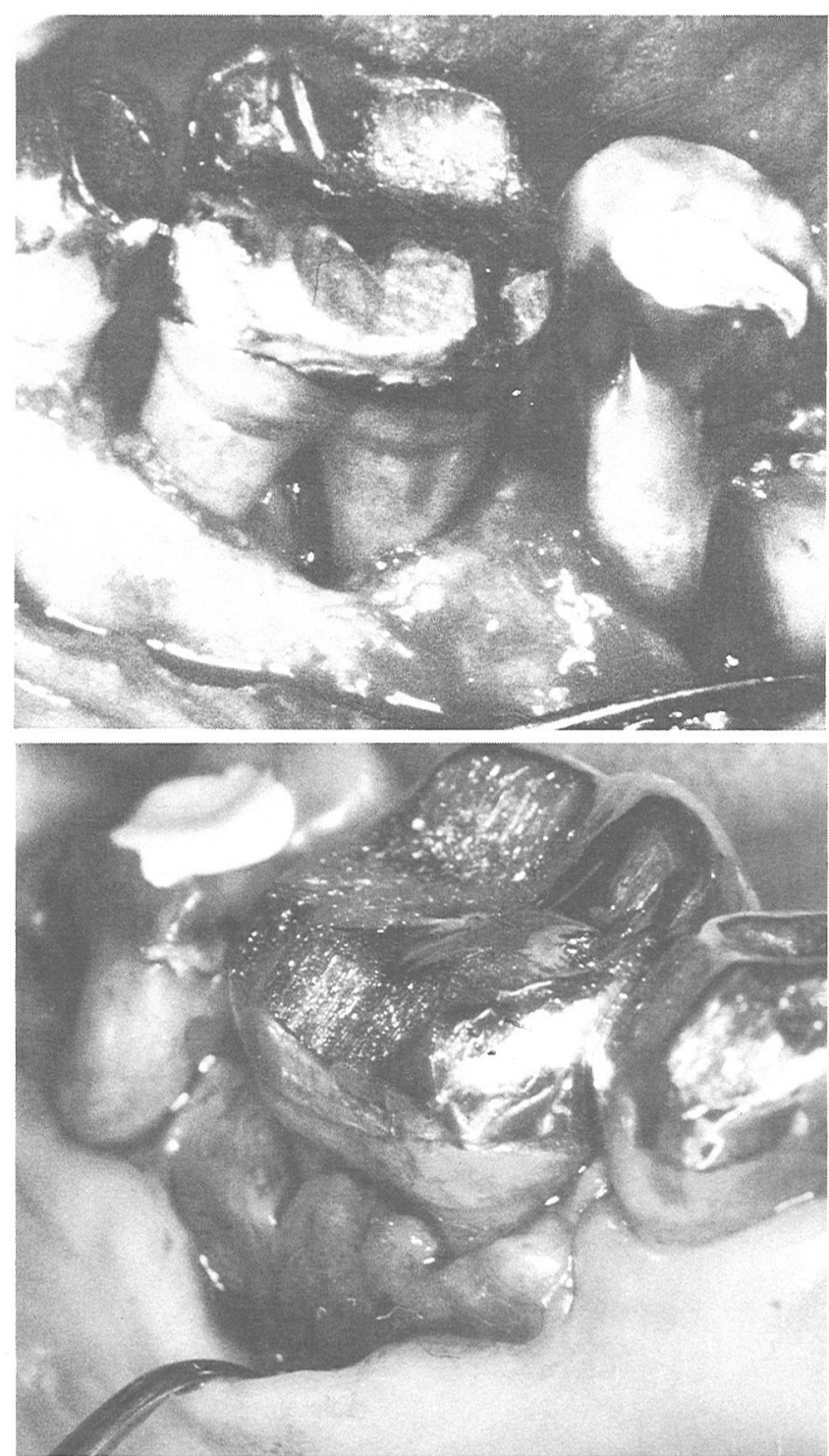
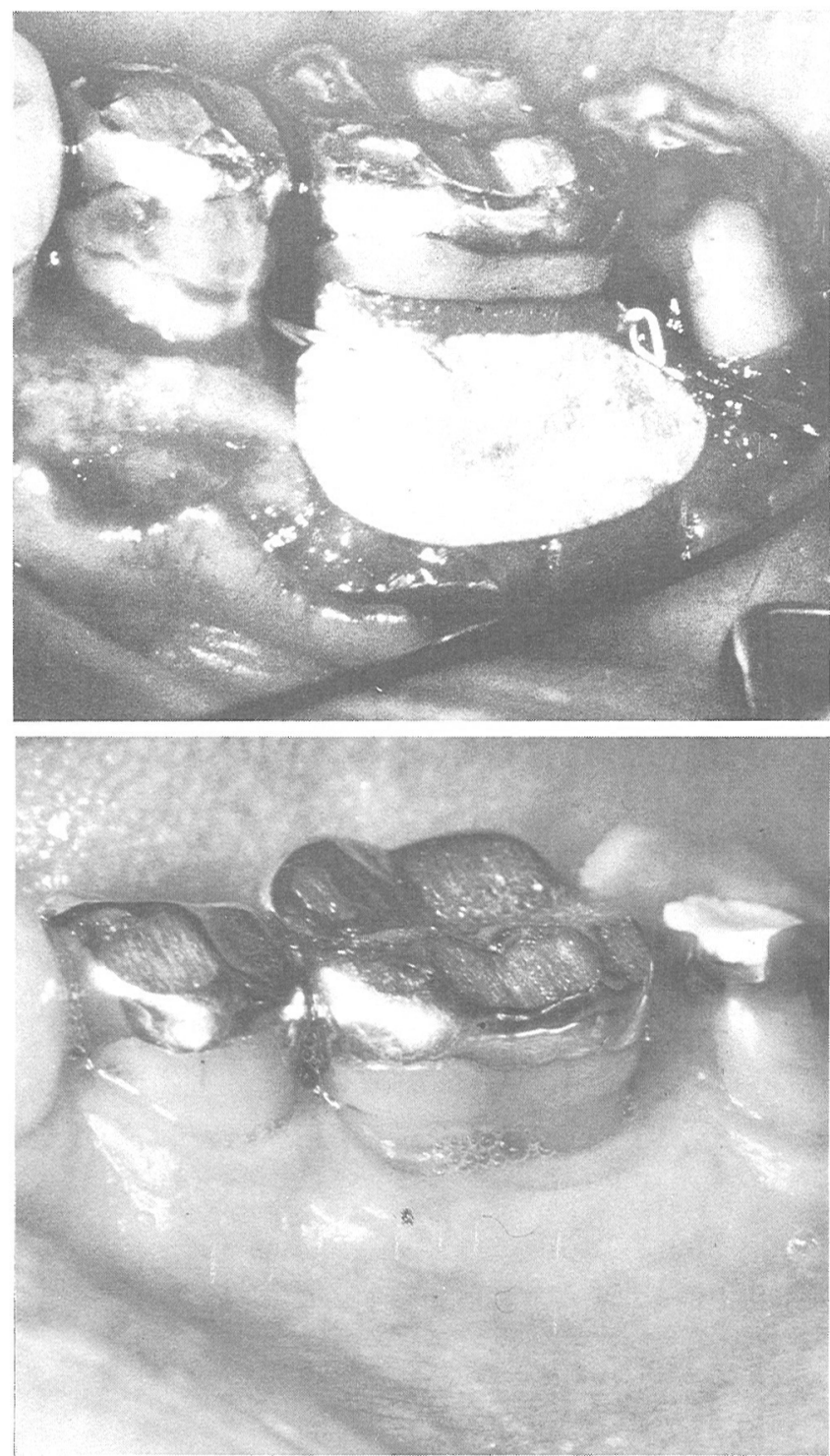

Figure 1: A. Class II furcation exposed during surgery; B. Gore-Tex periodontal material adapted and sutured to the tooth with a suspensory suture; C. 6 weeks post-surgery at time of membrane retrieval; observe the tissue filling the furcation which has grown under the membrane; D. 6 months postoperatively.

Table 1: Plaque and Gingival Index Values for Test and Control Teeth at Different Observation Times

\begin{tabular}{lccccc}
\hline & \multicolumn{2}{c}{ Plaque Index } & & \multicolumn{2}{c}{ Gingival Index } \\
\cline { 2 - 3 } \cline { 6 - 6 } Time & Test & Control & & Test & Control \\
\hline Baseline & 0.82 & 0.67 & & 1.72 & 1.00 \\
3 months & 1.00 & 0.85 & & 0.81 & 0.83 \\
6 months & 1.00 & 1.33 & & 1.00 & 1.17 \\
\hline
\end{tabular}

and $2.4 \mathrm{~mm}$ for the controls with clinical attachment gain of $3.5 \mathrm{~mm}$ and $1 \mathrm{~mm}$, respectively. The improvement achieved in our values are not as pronounced as those reported by Pontoriero et al. ${ }^{13}$ Perhaps the most significant difference in study design, which could explain these diverse results, is the fact that all their subjects were seen every 2 weeks for professional tooth cleaning, while the subjects in our study received professional prophylaxis only at 3-month intervals. As it has been shown previously, this closely monitored regimen of maintenance could affect positively the results achieved with any type of periodontal treatment. Furthermore, most of the patients treated in the present study have been on periodontal maintenance for some time, which stresses the chronic condition of the furcation involvements treated.

The difference in the maintenance regimen could also be responsible for the differences in the results observed in these two studies in the complete closure of the furcations. In spite of the improvement registered, we did not observe any furcation completely closed. Our result agrees with that reported by Becker et al. ${ }^{11}$ previously.

The use of guided tissue regeneration produces better results in the treatment of Class II furcation defects. In 
Table 2: Probing Pocket Depths* for Test and Control Teeth

\begin{tabular}{lccccccc}
\hline & \multicolumn{3}{c}{ Test } & & \multicolumn{3}{c}{ Control } \\
\cline { 2 - 4 } \cline { 6 - 7 } Subject & Baseline & 3 months & 6 months & & Baseline & 3 months & 6 months \\
\hline 1 & 7.0 & 3.5 & 5.0 & & & \\
2 & 4.5 & 4.0 & 3.5 & & 4.0 & 5.0 & 3.0 \\
& & & & 3.0 & 3.0 & 3.0 \\
3 & 6.0 & 3.0 & 4.0 & & & \\
4 & 5.5 & 3.0 & 2.0 & & 6.5 & 4.5 & 4.5 \\
5 & 5.0 & 3.0 & 1.5 & & & \\
& 10.0 & 6.0 & 5.0 & & & \\
6 & 6.0 & 2.0 & 1.5 & & 3.0 & 3.0 & 2.5 \\
7 & 5.5 & 2.0 & 3.5 & & 4.0 & 2.5 & 2.0 \\
8 & 5.0 & 2.5 & 2.0 & & 4.5 & 3.0 & 2.0 \\
9 & 5.0 & 1.5 & 2.5 & & & \\
Mean & 5.0 & 3.0 & 1.5 & & & \\
SD & 5.7 & 3.0 & 2.9 & & 4.5 & 3.6 & 2.9 \\
& 1.0 & 0.9 & 1.1 & & 1.4 & 0.8 & 1.1 \\
\hline
\end{tabular}

*All measurements are in $\mathrm{mm}$.

Table 3: Mean Difference in Probing Depths* for Test and Control Teeth

\begin{tabular}{lccccc}
\hline & \multicolumn{3}{c}{ Test } & & \multicolumn{2}{c}{ Control } \\
\cline { 2 - 3 } \cline { 5 - 6 } Subject & 3 months & 6 months & & 3 months & 6 months \\
\hline 1 & 3.5 & 2.0 & & \\
2 & 0.5 & 1.0 & & 1.0 & 1.0 \\
3 & 3.0 & 2.0 & & 0.0 & 0.0 \\
4 & 2.5 & 3.5 & & 2.0 & 2.0 \\
5 & 2.0 & 3.5 & & \\
& 4.0 & 6.0 & & 0.0 & 0.5 \\
6 & 4.0 & 4.5 & & & \\
& 3.5 & 2.0 & & 1.5 & 2.0 \\
7 & 2.5 & 3.0 & & 1.5 & 2.5 \\
8 & 3.5 & 2.5 & & \\
9 & 2.0 & 3.5 & & \\
Mean & 2.7 & 2.8 & & 0.9 & 1.6 \\
SD & 1.0 & 1.0 & 1.1 & 0.9 \\
\hline
\end{tabular}

*All measurements are in $\mathrm{mm}$.

Table 4: Probing Attachment Levels* for Test and Control Teeth at Different Observation Times

\begin{tabular}{lccccccc}
\hline & \multicolumn{3}{c}{ Test } & & \multicolumn{3}{c}{ Control } \\
\cline { 2 - 4 } \cline { 7 - 8 } Subject & Baseline & 3 months & 6 months & & Baseline & 3 months & 6 months \\
\hline 1 & 8.0 & 4.5 & 6.0 & & & \\
2 & 5.5 & 4.5 & 4.0 & & 6.0 & 8.0 & 6.0 \\
3 & 7.5 & 6.0 & 5.5 & & 3.0 & 3.0 & 5.0 \\
4 & 5.5 & 5.0 & 3.0 & & 8.5 & 5.0 & 6.5 \\
5 & 4.0 & 4.0 & 2.0 & & & \\
6 & 9.0 & 4.0 & 6.0 & & & \\
6 & 5.0 & 3.0 & 3.0 & 2.0 & 3.0 & 3.0 \\
7 & 4.5 & 3.0 & 3.5 & & 2.0 & 2.5 & 3.0 \\
8 & 3.5 & 5.0 & 5.0 & 6.5 & 5.0 & 4.0 \\
9 & 5.0 & 5.0 & 2.5 & & & \\
Mean & 7.5 & 4.5 & 4.5 & & & \\
SD & 6.0 & 4.6 & 4.2 & & 5.4 & 4.6 & 4.8 \\
& 1.5 & 0.8 & 1.2 & 2.8 & 1.2 & 1.6 \\
\hline
\end{tabular}

*All measurements are in $\mathrm{mm}$.

future studies, the advantages of combining this approach with other modalities designed to achieve regeneration, such
Table 5: Mean Differences in Attachment Levels* for Test and Control Teeth

\begin{tabular}{lccccc}
\hline & \multicolumn{2}{c}{ Test } & & \multicolumn{2}{c}{ Control } \\
\cline { 2 - 3 } \cline { 5 - 6 } Subject & 3 months & 6 months & & 3 months & 6 months \\
\hline 1 & 3.5 & 2.0 & & 2.0 & 0.0 \\
2 & 1.0 & 1.5 & & 0.0 & 2.0 \\
3 & 1.5 & 2.0 & & \\
4 & 0.5 & 2.5 & & 3.5 & 2.0 \\
5 & 0.0 & 2.0 & & 1.0 & -1.0 \\
& 5.0 & 3.0 & & -1.0 & -1.0 \\
6 & 2.0 & 2.0 & & 0.5 & -1.0 \\
& 1.5 & 1.0 & & \\
7 & 1.5 & -1.5 & & 1.5 & 2.5 \\
8 & 0.0 & 2.5 & & & \\
9 & 3.0 & 3.0 & & & \\
Mean & 1.4 & 1.8 & & 0.8 & 0.6 \\
SD & 1.6 & 1.3 & 2.2 & 1.9 \\
\hline
\end{tabular}

*All measurements are in $\mathrm{mm}$.

Table 6: Mean Horizontal Attachment Levels for Test and Control Furcations at Different Time Intervals

\begin{tabular}{lll}
\hline Time & \multicolumn{1}{c}{ Test } & Control \\
\hline Baseline & $4.82(2-11)^{*}$ & $5.25(3-7)$ \\
3 Months & $3.56(2-6)$ & $3.5(2-7)$ \\
6 Months & $4.00(1-7)$ & $5.0(2-8)$ \\
\hline
\end{tabular}

* Mean (range)

as bone grafting, root demineralization, attachment proteins, and/or coronally positioned flaps, need to be explored and properly evaluated. Within the limits of this report, guided tissue regeneration can improve the response to therapy of Class II furcation defects.

\section{Acknowledgments}

This project was partially supported by W.L. Gore and Associates, Flagstaff, AZ.

\section{REFERENCES}

1. Nyman S, Gottlow J, Karring T, Lindhe J. The regenerative potential of the periodontal ligament. An experimental study in the monkey. $J$ Clin Periodontol 1982; 9:257.

2. Nyman S, Lindhe J, Karring T, Rylander H. New attachment following surgical treatment of human periodontal disease. $J$ Clin Periodontol 1982; 9:290.

3. Nyman S, Lindhe J, Karring T. Reattachment - new attachment. In: Textbook of Clinical Periodontology. Lindhe J, Ed. Copenhagen: Munksgaard; 1983:410-432.

4. Aukhil 1, Simpson DM, Schaberg TV. An experimental study of new attachment procedure in beagle dogs. J Periodont Res 1983; 18:643.

5. Magnusson I, Nyman S, Karring T, Egelberg J. Connective tissue attachment formation following exclusion of gingival connective tissue and epithelium during healing. $J$ Periodont Res 1985; 20:201.

6. Aukhil I, Pettersson E, Suggs C. Guided tissue regeneration: An experimental procedure in beagle dogs. J Periodontol 1986; 57:727.

7. Caffesse RG, Smith BA, Castelli WA, Nasjleti CE. New attachment achieved by guided tissue regeneration in beagle dogs. $J$ Periodontol 1988; 59:589.

8. Nyman S, Gottlow J, Lindhe J, et al.: New attachment formation by guided tissue regeneration. $J$ Periodont Res 1987; 22:252. 
9. Gottlow J, Nyman S, Lindhe J, et al. New attachment formation in the human periodontium by guided tissue regeneration. Case reports. $J$ Clin Periodontol 1986; 13:604.

10. Becker W, Becker BE, Prichard JF, et al. Root isolation for new attachment procedures: A surgical and suturing method. Three case reports. J Periodontol 1987; 58:819.

11. Becker W, Becker BE, Berg L, et al. New attachment after treatment with root isolation procedures: Report of treated class III and class II furcations and vertical osseous defects. Int $J$ Periodontics Restorative Dent 1988; 8(3):9-23.

12. Pontoriero R, Nyman S, Lindhe J, et al. Guided tissue regeneration in the treatment of furcation defects in man. J Clin Periodontol 1987; 14:618.

13. Pontoriero R, Lindhe J, Nyman J, et al. Guided tissue regeneration in degree II furcation-involved mandibular molars. A clinical study. J Clin Periodontol 1988; 15:247.

14. Silness J, Löe H. Periodontal disease in pregnancy. II. Correlation between oral hygiene and periodontal condition. Acta Odont Scand 1964; 22:112.

15. Löe H, Silness J. Periodontal disease in pregnancy. I. Prevalence and severity. Acta Odont Scand 1963; 21:533.

16. Ramfjord S. The periodontal disease index (P.D.I.). J Periodontol $1967 ; 38: 602$.

Send reprint requests to: Dr. Raul G. Caffesse, Department of Periodontics, The University of Texas Health Science Center at Houston, Dental Branch, 6516 John Freeman Avenue, Houston, TX 77030. Accepted for publication January 29, 1990. 